\title{
The lipid network
}

\author{
Marc-Antoine Sani • Frances Separovic • \\ John D. Gehman
}

Received: 15 January 2012 / Accepted: 10 February 2012 / Published online: 24 March 2012

(C) International Union for Pure and Applied Biophysics (IUPAB) and Springer 2012

\begin{abstract}
Natural cell membranes are composed of a remarkable variety of lipids, which provide specific biophysical properties to support membrane protein function. An improved understanding of this complexity of membrane composition may also allow the design of membrane active drugs. Crafting a relevant model of a cell membrane with controlled composition is becoming an art, with the ability to reveal the molecular mechanisms of biological processes and lead to better treatment of pathologies. By matching physiological observations from in vivo experiments to high-resolution information, more easily obtained from in vitro studies, complex interactions at the lipid interface are determined. The role of the lipid network in biological membranes is, therefore, the subject of increasing attention.
\end{abstract}

Keywords Model membrane $\cdot$ Lipid composition $\cdot$ Lipid transformation $\cdot$ Lipid targeting $\cdot$ Membrane active peptides

\section{Introduction}

Knowledge of cellular mechanisms has been obtained by relating in vitro and in vivo observations. In situ studies of highly entangled cell networks provide us with challenging hypotheses that high-resolution experiments using cell models try to validate or vice-versa. In general, membrane-active molecules respond differently to specific lipid compositions, which can be encountered either within a single cell membrane - such as a lipid domain — or by trafficking through

M.-A. Sani $(\bowtie) \cdot$ F. Separovic $\cdot$ J. D. Gehman

School of Chemistry, Bio21 Institute, University of Melbourne, Melbourne, VIC 3010, Australia

e-mail:msani@unimelb.edu.au different membrane layers. As the variety of lipids is linked progressively to cellular regulation, it is becoming important to craft relevant membrane models and to analyze information obtained from different lipid compositions. This review begins with a brief overview of the history of lipids and model membranes before expanding on the differences obtained using natural membranes, membrane models and between models of various lipid compositions. Finally, how membrane complexity due to the diversity of the lipid components can be used to advantage for specific targeting will be described.

\section{A complex network builds over a century}

The immense variety of lipids was not immediately obvious. The term lipid itself has evolved; it was first used by Sperry in 1926 (Sperry 1926) and definitively adopted in 1960, competing until then with the terms lipoid or lipide. Meanwhile, numerous lipid structures were determined, amongst the first being that of the phosphatidylcholine structure from egg yolk in 1874 by the French scientist Gobley. The sense of diversity already existed in this period due to the exponential rate of discovery of different fatty acids that constitute the acyl chains of lipids.

Between the two world wars, the renowned structure elucidation of cholesterol led to two Nobel prizes, in 1927 (Windaus and Wieland with the chemical structure) and 1937 (Crowfoot-Hodgkin with the first X-ray crystal structure). The main phospholipids were discovered between 1941 with cardiolipin (CL) (Pangborn 1941) then phosphatidylethanolamine (PE), phosphatidylserine (PS) in 1942 (Folch 1942), phosphatidylglycerol (PG) in 1958 (Benson and Maruo 1958) and finally phosphatidylinositol (PI) in 1959 (Pizer and Ballou 1959). The ceramide and ganglioside lipid structures were resolved in the 1960s (Klenk and Padberg 1962; Kuhn and 
Egge 1963; Kuhn and Wiegandt 1963; LaBach and White 1969 ) as post-synthesis modifications of bacterial lipids headgroups by amino-acid addition (Macfarlane 1962). Lipopolysaccharide and lipid A structure determinations were achieved in the mid-1980s (Takayama et al. 1983), and acyl chain modifications were discovered in 1980 (Porter et al. 1980), illustrating the diversity of lipid species composing the vitaland functional-cell membranes of all living organisms (Fig. 1).

\section{Evolution of understanding of lipid membranes}

The original ideas of cell membranes composed of lipids came from the work of Quincke in 1888, later confirmed by Overton in 1895 , when cell permeability to ionic and hydrophobic molecules was studied. The concept of lipid self-organization into a monolayer at the water-air interface was demonstrated by Langmuir in 1917. He used the initial work of Pockels, and indeed even her sink, to make the now famous Langmuir trough. Eight years later, Gorter and Grendel extracted lipids from red blood cells and came to the conclusion that lipids were assembled into bilayers if the area per lipid and the cell surface were to match (Gorter and Grendel 1925). The first attempt to describe a cell membrane model was made by Danielli and Dawson in 1935 (Danielli and Davson 1935). They described how lipids form a bilayer sandwiched by a layer of proteins, erroneously confirmed by Schmidt and Palmer using X-ray techniques (1941) (Palmer and Schmitt 1941; Palmer et al. 1941). This marked the explosion of structural work using high-resolution techniques. Robertson observed the first organelle membranes using electron microscopy in 1957 and came up with the "unit membrane" or railroad track model (Robertson 1957).

The use of extracted phospholipids to reconstitute cell membranes was achieved by Bangham in 1965 (Bangham et al. 1965a) and the term liposome was coined. Summarizing several observations from in vivo to in vitro studies, Singer and Nicolson determined that cell membranes were highly fluid and homogeneous and established the fluid mosaic model in 1972 (Singer and Nicolson 1972), where proteins are rapidly diffusing in a "sea" of lipids. Following this period, several biophysical concepts flourished: lipid phases (Chapman 1975; Marsh 1991), lipid domains (Karnovsky et al. 1982; Stier and Sackmann 1973), membrane plasticity (Chapman 1988; Gitler and Rudy 1972), lipid polymorphism

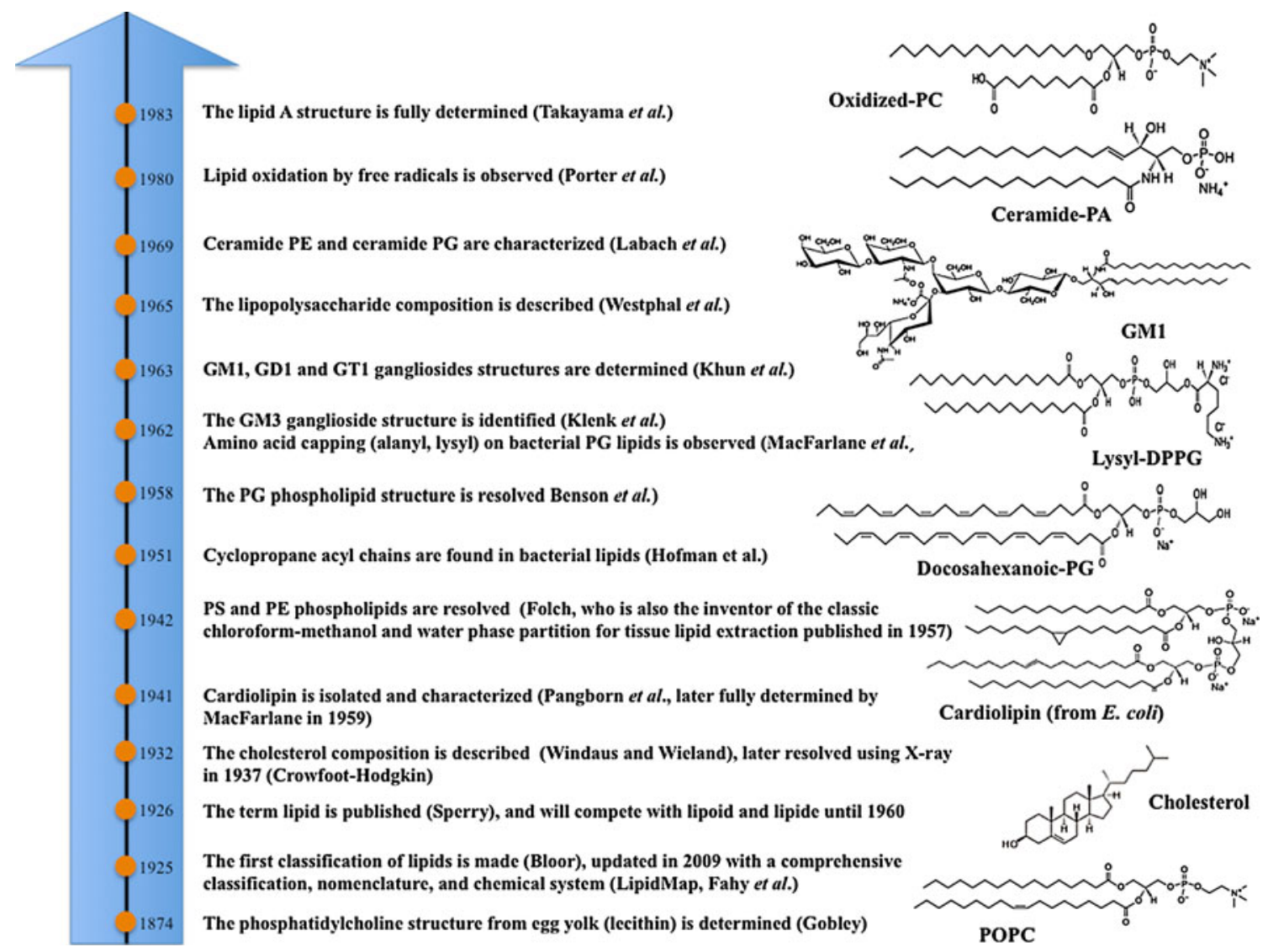

Fig. 1 Timeline of various lipid discoveries. POPC 1-palmitoyl-2oleoyl-sn-glycero-3-phosphocholine. $P G$ glycero-3-phosphoglycerol. $D P P G$ 1,2 -dipalmitoyl-sn-glycero-3-phosphoglycerol. GM1 monosialotetrahexosylganglioside. $P A$ glycero-3-phosphatidic acid. $P E$ glycero-3-phosphoethanolamine. $P S$ glycero-3-phosphoserine. $P I$ glycero-3-phosphoinositol 
(Cullis and de Kruijff 1979), membrane asymmetry (Rothman and Lenard 1977), and the lipid raft model (1988) (Simons and Ikonen 1997), while more recently the lipid whisker models of oxidized lipids (2008) (Greenberg et al. 2008) refined our understanding of lipid membrane functionalities. But, despite the tremendous advances in high-resolution techniques, it is still difficult to control membrane organization, lipid structures, and interplay with proteins in order to understand cellular processes. The common strategy to overcome these difficulties is to match in vivo functional information with in vitro structural data using relevant membrane models (Fig. 2).

\section{Influence of specific lipid composition on protein function}

Crafting membrane models is becoming a trying task as more and more lipids are discovered, purified, and characterized. In order to assess the role of specific lipid structures in modulating protein function, a simple strategy is to form models of minimal lipid composition and evaluate the relevance of the structural information obtained with physiological observations.

A simple and probably the most used lipid class is diacyl phosphatidylcholine (PC). This was considered to be the most important lipid in eukaryotic cells because PCs represent the largest part of organelle membranes and readily form liposomes, bilayers arranged in spherical structures, in aqueous phase (Bangham et al. 1965b; Huang 1969; Papahadjopoulos and Miller 1967). PC liposomes are well characterized and used as a template of many cell systems, but in many cases do not reflect a sufficient or adequate lipid environment for proteins to function properly. Indeed, the layer surrounding a membrane protein - the annular lipids - must have the right biophysical properties (rigidity, hydrophobic thickness, electrostatic potential, structure) to render a protein fully functional (Contreras et al. 2011; Epand 2007; Marsh 2008). For

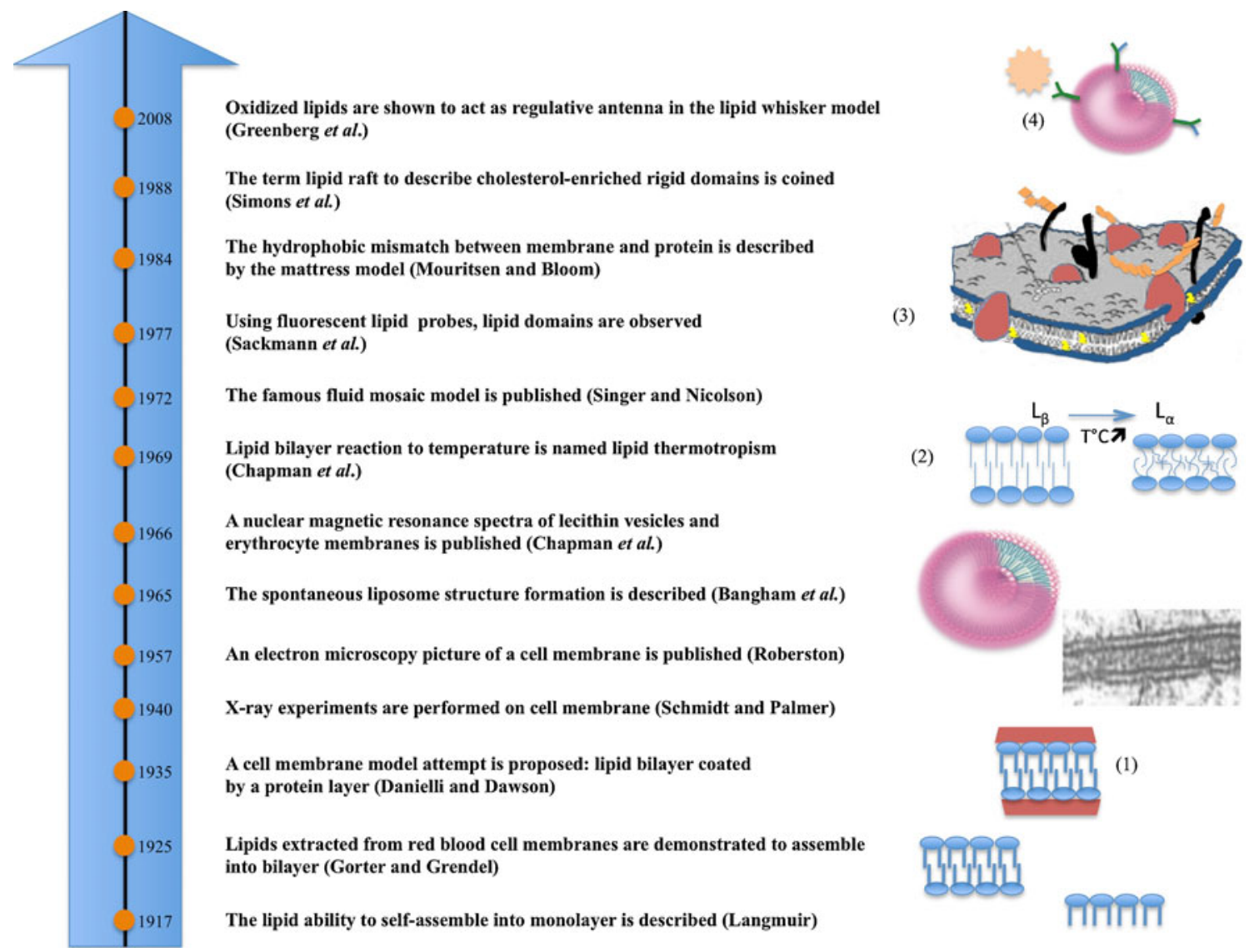

Fig. 2 Timeline of membrane structure conception. (1) Danielli and Dawson's model of the protein layer (red) coating the lipid bilayer (blue). (2) In the gel $\mathrm{L}_{\beta}$ phase , acyl chains are rigid; increasing the temperature promotes transition to the liquid-crystalline $\mathrm{L}_{\alpha}$ phase where acyl chains are highly disordered. (3) Singer and Nicolson's fluid mosaic model: the membrane model is described to be fluid because of lipids (blue/grey) and proteins (red) diffuse laterally, meaning the membrane is not solid. The membrane is depicted as mosaic because it is composed of many macromolecules having different properties, such as glycolipids (black) or cholesterol (yellow). (4) The lipid whisker model represents the latest evolution in membrane structure and function understanding. When lipids acyl chains are oxidized (green), they become hydrophilic and are exposed towards the aqueous phase, serving as signal receptor for molecules such as enzymes (béchamel) 
instance, HorA, a bacterial ATP-binding cassette multidrug transporter, was shown to lose ATP hydrolysis and substrate transport functions when the protein was reconstituted in PC vesicles instead of PE vesicles, the main lipid of bacterial membranes (Gustot et al. 2010). The structural modifications of the protein were insignificant while the important change was observed in the transmembrane segment (TM) orientation where the helices opened wider by $10^{\circ}$ in PE- versus PC-containing vesicles. In this case, comparing observations from two models composed of a single lipid seems straightforward, but as natural membranes are composed of a multitude of lipids, the relevance of these observations needs further investigation.

Alzheimer's disease offers a prime example of the difficulty in comparing observations from slightly more complex models. In this severe pathology affecting aging populations, the death of neurons may be linked to the aggregation of the amyloid-beta $(A \beta)$ peptides on neuronal membrane, and many studies have tried to correlate the formation of amyloid fibrils with a specific lipid environment (Gehman and Separovic 2011; Di Paolo and Kim 2011; Sani et al. 2011a). Liposomes made of PC/PE, PC/GM1 or PC/PS were used to pinpoint the effect of a specific lipid (Sani et al. 2011a). Large differences in aggregation kinetics and fibril morphologies were observed: electrostatic interactions induced by anionic lipid (PS) delayed the fibril formation but produced long and thin fibrils while steric effects with the bulky GM1 lipids or interaction with the tight PE surface induced fast-forming and coarse fibrils. Meanwhile, to determine toxicity, comparisons with observations on live neuronal cells are necessary. The aggregation of $\mathrm{A} \beta$ peptides on live neuroblastoma cells showed that cellbound $A \beta$ oligomer size distribution is shifted towards larger aggregates (Johnson et al. 2011). The lipid matrix either triggered a rapid increase in aggregate size or the oligomers clustered at specific sites on the membrane. Is it possible that the pathologic aggregation of $A \beta$ is associated with a specific lipid environment? Cecchi et al. demonstrated that $A \beta$ aggregation was less toxic against undifferentiated cognate cell models than with differentiated neuron cells containing higher amounts of GM1 (Cecchi et al. 2011). Reducing the PE content by nearly $50 \%$ in differentiated human neuroblastoma cells dramatically decreased the neurotoxicity of $A \beta$ peptides in another study (Cazzaniga et al. 2011). Although unable to conclude any specific role of a particular lipid - it could simply be that $A \beta$ forms different fibril types at different rates in different lipid environments-lipids do play a role. However, even data from real cell systems and controlled membrane models, can lead to ambiguity, often delaying the cure of severe pathologies. The effect of different lipid compositions on membrane active molecules is discussed in the following examples.

\section{Specific lipid affinity of antimicrobial peptides in bacterial membrane models}

Eukaryotic and prokaryotic cells have little resemblance in their lipid composition-a good thing! Symbiosis is sometimes highly beneficial for both species but, on other occasions, a deadly war occurs at the membrane interface. Gramnegative bacteria can expose glycolipids - or lipopolysaccharides - on their external membrane surface, which act as endotoxins, stimulating immune response and inflammation in eukaryotic cells. To fight microbial infection, antibiotics were made but have become ineffective when facing evolved mutants, which are increasing dangerously in number (Andersson and Hughes 2011; Canton and Morosini 2011). To fight these new superbug generations, natural host defense peptides - or antimicrobial peptides (AMP) - are being studied intensively for their ability to disrupt membranes of specific lipid compositions (Brown and Hancock 2006; Fernandez et al. 2011; Hadley and Hancock 2010; Lohner 2009; Epand and Epand 2011; Lundbaek et al. 2010; Sani et al. 2011b; Shai 2002). AMP affinity for bacterial membrane is generally triggered by electrostatic interactions: the positive cationic peptides interact preferentially with negatively charged anionic lipids, PG and CL (Lohner and Prossnigg 2009; Epand and Epand 2011). Contrastingly, they have low affinity for eukaryotic membranes, which are usually neutral with high concentration of cholesterol that decreases the lipid membrane permeability. Thus, it seems straightforward to compare AMP interactions with membrane models of composition mimicking bacterial and eukaryotic cells. The impact of diverse lipid acyl chains and headgroup structures can then be individually assessed, providing valuable information in understanding how these peptides 'see' the bacterial membrane.

AMP activity can depend strongly on a specific interaction with a particular lipid structure. Cyclic synthetic arginine or tryptophan-rich AMP peptides have minimal effect against PE/PG membranes but interact strongly with $\mathrm{PC}$, promoting permeabilization of neutral membranes. However, these peptides are highly potent against $E$. coli and removal of the bacterial outer membrane drastically reduces peptide activity. LPS-doped PC membranes demonstrated the decisive role of $\mathrm{O}$-antigen and outer core polysaccharides for peptide binding and partitioning (Bagheri et al. 2011; Junkes et al. 2011). The role of LPS - but not PG-as a critical partner is further shown for the NK2 peptide - another porcine AMP. Indeed, the weak interaction with PG membranes could not explain the bactericidal activities against $E$. coli bacteria (Hammer et al. 2010; Willumeit et al. 2005). Using LPS extracted from $E$. coli and P. mirabilis, the differences in activity could be identified in the LPS-binding step where the net charge and charge distribution difference of the two LPS was proposed to be responsible for the specific activities (Hammer et al. 2010). 
The porcine AMP PG1 inserted into anionic membranes composed of PG and lipid A (precursor of LPS) or into neutral PC membranes but not in PE lipids, which mostly constitute bacterial plasma membranes, confirming that not only the charge of the membrane surface but also the fine structure of the headgroup is an important parameter for AMP activity. On the Gram-positive side, the lantibiotic nisin combines targeting of lipid II (precursor of peptidoglycans) with membrane permeabilization (Wilmes et al. 2011). Nisin bound to the pyrophosphate moiety of lipid II and induced a stable membrane pore. Although interaction between the cationic peptide and the negatively charged model membranes is observed in vitro, nisin and various defensins have been shown to inhibit the cell wall biosynthesis by segregating the lipid II (Schneider et al. 2010; Wiedemann et al. 2001). Furthermore, lipid modification in bacteria changes the effect of membraneactive molecules. For instance, the aminoacylation of PG and teichoic acid lipids in the Gram-positive $S$. aureus is indicated as a potential cause of AMP resistance because it increases the positive charges on the bacterial membrane surface, to ultimately "hide" the electrostatic attraction with cationic peptides (Andra et al. 2011; Peschel 2002). Similar modification of LPS and lipid A were also observed in Gram-negative bacteria, where the addition of the amino acyl group reduced the binding of cationic molecules (Koprivnjak and Peschel 2011).

Not only can phospholipid headgroup charge and structure modulate interactions between AMP and membranes but acyl chains also appear to play a very important part. LL-37-a human AMP - induced a quasi-interdigitated phase in negatively charged PG model membranes, and promoted disk-like micelles in neutral C16 PC (16 carbons long acyl chains) bilayers, but induced interdigitation in longer chain C18 and C20 PC bilayer membranes (Sevcsik et al. 2007). PG1-a porcine AMP - inserted into anionic membranes composed of PG and lipid A (precursor of LPS) or PC. But an increase in acyl chain saturation or incorporation of sterols, which both enhance the rigidity of the membrane hydrophobic core, reduced the ability of PG1 to insert deep into the membrane (Gidalevitz et al. 2003). Modifications occur in the life cycle of bacteria that also change the fluidity of the bacterial membrane, and thereby the potential insertion of AMP into the lipid hydrophobic core. Bacteria can modulate their lipid structure and composition during their growth. For instance, on entering the stationary phase after their exponential growth, bacterial membranes displayed higher amounts of branched and cyclopropane acyl chains (Grogan and Cronan 1997). In $L$. pneumophila, modifications of the acyl chains produced a resistant strain against the AMP warnericin RK (Verdon et al. 2011). Also, B. infantis was resistant to rifaximin due to an increase in the amount of cyclopropane and saturated acyl chains, which induced a reduction in membrane permeability for the antibiotic moiety (Vitali et al. 2008). Using solid-sate NMR, Dufourc et al. demonstrated that incorporation of a cyclopropane ring decreased the fluidity of the acyl chain core from the bilayer surface to the site of the cyclopropane ring, with a much more disordered region thereafter to the center of the bilayer (Dufourc et al. 1983). A similar decrease in the temperature of the gel to liquidcrystal phase transition and a very significant broadening of the transition profile was observed in PC and PE membrane models. The cyclopropane-containing chains had a poor packing ability due to the bulky substituent effect (Perly et al. 1985) and may change the interaction of AMP with bacterial membrane during the growth cycle.

Overall, the balance between electrostatic interactions, specific recognition, and penetration depth driven by hydrophobic interactions modulates very complex molecular mechanisms that cannot be simply studied with classic model membranes. Recently, the use of complex lipids, such as LPS, lipid A, or lipid II, demonstrated their crucial roles in either enabling AMP to rupture the plasma membrane. It remains critical to improve the membrane models to reach relevant information that will improve the design of more potent and more specific membrane active molecules.

\section{High-resolution structure in live cells}

The best model of natural cell membrane is the living cell. Until recently, molecular structure was limited to simple membrane models, such as PC micelles. The in-cell NMR, developed by Dotsch and co-workers, has overcome this limitation. They impressively resolved the structure of over-expressed proteins in situ (Serber et al. 2001, 2006). In 2001, they clearly demonstrated that the structure of mercury-detoxification MerA bacterial protein, overexpressed in $E$. coli, differed from in vitro models (Serber and Dotsch 2001). This technique is constantly improved and is a valuable way of providing the most relevant structural information (Maldonado et al. 2011; Selenko and Wagner 2007). Recently, the technique was applied to study membrane proteins, a very difficult task due to the resolution and stability limitations induced by the lipid environment. Fu and co-workers successfully managed to refine the TM segment of an apolipoprotein E receptor, LR11, involved in Alzheimer's disease, using an in-cell solid-state NMR approach (Fu et al. 2011). They compared the secondary structure of the TM segment of LR11 in native membrane and PC micelles and found minor discrepancies between the two environments. Although bacterial membranes are not representative of eukaryotic cell membranes, this approach has many attractive advantages: little manipulation of the protein, such as purification and refolding steps, and investigation in situ where membrane heterogeneity and cellular activities are more realistic. Ultimately, 
the use of eukaryotic living cells will provide an even better environment for native proteins.

In a similar approach, high-resolution experiments were conducted on live mitochondria with a focus on membrane structure alterations. In 2009, Sani and co-workers were able to characterize the response of ex vivo mitochondrial membranes under calcium stress (Sani et al. 2009). The integrity of this organelle was preserved under magic angle spinning conditions in solid-state NMR experiments, and a clear change in membrane was observed upon calcium overload. Interestingly, the resolution was sufficient to identify the main phospholipids comprising the mitochondrial membrane (PE, PC, and CL), which permitted tracking of individual lipid response. Combined with physiological experiments, only the outer membrane was shown to be altered by calcium stress. In situ, calcium did not interact with the inner membrane where most of CL lipids are located. This was an unexpected result as calcium has been shown to induce strong alterations in mitochondrial membrane models containing CL lipids by inducing hexagonal structures (Cullis et al. 1978; Macdonald and Seelig 1987). Correlation of in vitro data to in vivo results is rarely a straightforward task; live cells will remain extremely heterogeneous with unique lipid compositions, while membrane models are simply unable to reflect the diversity of interactions modulating cellular mechanisms.

Natural cell membranes are obviously the best system to use, but their individual complexity, fragility, and tedious low yield extraction (especially eukaryotic organelles) motivate the continued use of membrane models. Highresolution information is more easily obtained from in vitro studies, it is only the relevance with the biological context that remains the main issue.

\section{Perspective}

As we advance our knowledge on the lipid diversity and functionality of each molecular species existing in biological membranes, new perspectives in the regulation of cellular mechanisms appear. Lipids are now recognized as potent signaling molecules and, therefore, offer targets to design novel therapeutic treatments. Improvements in mass spectrometry are enabling fast and accurate screening of complex membrane compositions, and composing a membrane model better resembling a natural cell is almost achievable. However, many biophysical properties are still to be described as new membrane compositions, organization, and structure continue to be discovered. Although models are often restricted by the requirements of the experimental technique, their constant improvement will provide better correlation between in vitro and in vivo studies. Techniques that allow monitoring of living cell membranes at atomic or molecular resolution are still to be improved, but experimental limitations are constantly pushed further away, building up our understanding of a lipid network composed of thousands of potential regulative lights.

Acknowledgments The work was supported by Australian Research Council Discovery grant DP0984815 and by a seed and early career research grants (University of Melbourne). I am also particularly grateful to Prof. Cristobal Dos Remedios for insightful discussions.

Conflict of interest None.

\section{References}

Andersson DI, Hughes D (2011) Persistence of antibiotic resistance in bacterial populations. FEMS Microbiol Rev 35(5):901-911

Andra J, Goldmann T, Ernst CM, Peschel A, Gutsmann T (2011) Multiple peptide resistance factor (MprF)-mediated Resistance of Staphylococcus aureus against antimicrobial peptides coincides with a modulated peptide interaction with artificial membranes comprising lysyl-phosphatidylglycerol. J Biol Chem 286(21):18692-18700

Bagheri M, Keller S, Dathe M (2011) Interaction of W-substituted analogs of cyclo-RRRWFW with bacterial lipopolysaccharides: the role of the aromatic cluster in antimicrobial activity. Antimicrob Agents Chemother 55(2):788-797

Bangham AD, Standish MM, Miller N (1965a) cation permeability of phospholipid model membranes - effect of narcotics. Nature 208 (5017): 1295

Bangham AD, Standish MM, Watkins JC (1965b) Diffusion of univalent ions across the lamellae of swollen phospholipids. J Mol Biol 13(1):238-252

Benson AA, Maruo B (1958) Piant phospholipids. I. Identification of the phosphatidyl glycerols. Biochim Biophys Acta 27(1):189-195

Brown KL, Hancock RE (2006) Cationic host defense (antimicrobial) peptides. Curr Opin Immunol 18(1):24-30

Canton R, Morosini MI (2011) Emergence and spread of antibiotic resistance following exposure to antibiotics. FEMS Microbiol Rev 35(5):977-991

Cazzaniga E, Bulbarelli A, Lonati E, Orlando A, Re F, Gregori M, Masserini M (2011) Abeta peptide toxicity is reduced after treatments decreasing phosphatidylethanolamine content in differentiated neuroblastoma cells. Neurochem Res 36(5):863-869

Cecchi C, Evangelisti E, Cascella R, Zampagni M, Benvenuti S, Luciani P, Deledda C, Cellai I, Wright D, Saccardi R, Peri A, Stefani M (2011) neuronal differentiation of human mesenchymal stromal cells increases their resistance to abeta42 aggregate toxicity. J Alzheimers Dis 27(3):651-664

Chapman D (1975) Phase transitions and fluidity characteristics of lipids and cell membranes. Q Rev Biophys 8(2):185-235

Chapman D (1988) Biomembrane structure and function: recent studies and new techniques. Parasitology 96(Suppl):S11-S23

Contreras FX, Ernst AM, Wieland F, Brugger B (2011) Specificity of intramembrane protein-lipid interactions. Cold Spring Harb Perspect Biol 3:a004705

Cullis PR, de Kruijff B (1979) Lipid polymorphism and the functional roles of lipids in biological membranes. Biochim Biophys Acta 559(4):399-420

Cullis PR, Verkleij AJ, Ververgaert PH (1978) Polymorphic phase behaviour of cardiolipin as detected by 31P NMR and freezefracture techniques. Effects of calcium, dibucaine and chlorpromazine. Biochim Biophys Acta 513(1):11-20 
Danielli JF, Davson H (1935) A contribution to the theory of permeability of thin films. J Cell Compar Physl 5(4):495-508

Di Paolo G, Kim TW (2011) Linking lipids to Alzheimer's disease: cholesterol and beyond. Nat Rev Neurosci 12(5):284-296

Dufourc EJ, Smith IC, Jarrell HC (1983) A 2H-NMR analysis of dihydrosterculoyl-containing lipids in model membranes: structural effects of a cyclopropane ring. Chem Phys Lipids 33(2):153177

Epand RM (2007) Membrane lipid polymorphism: relationship to bilayer properties and protein function. Methods Mol Biol 400:15-26

Epand RM, Epand RF (2011) Bacterial membrane lipids in the action of antimicrobial agents. J Pept Sci 17(5):298-305

Fernandez DI, Sani MA, Gehman JD, Hahm KS, Separovic F (2011) Interactions of a synthetic Leu-Lys-rich antimicrobial peptide with phospholipid bilayers. Eur Biophys J 40(4):471-480

Folch J (1942) Brain cephalin, a mixture of phosphatides. Separation from it of phosphatidyl serine, phosphatidyl ethanolamine, and a fraction containing an inositol phosphatide. J Biol Chem 146 (1):35-44

Fu R, Wang X, Li C, Santiago-Miranda AN, Pielak GJ, Tian F (2011) In situ structural characterization of a recombinant protein in native Escherichia coli membranes with solid-state magic-anglespinning NMR. J Am Chem Soc 133(32):12370-12373

Gehman JD, Separovic F (2011) Solid-state NMR of amyloid membrane interactions. Methods Mol Biol 752:165-177

Gidalevitz D, Ishitsuka Y, Muresan AS, Konovalov O, Waring AJ, Lehrer RI, Lee KY (2003) Interaction of antimicrobial peptide protegrin with biomembranes. Proc Natl Acad Sci USA 100 (11):6302-6307

Gitler C, Rudy B (1972) Implications of membrane plasticity. Abstr Pap Am Chem S 164(Aug-S):214

Gorter E, Grendel F (1925) On bimolecular layers of lipoids on the chromocytes of the blood. J Exp Med 41(4):439-443

Greenberg ME, Li XM, Gugiu BG, Gu X, Qin J, Salomon RG, Hazen SL (2008) The lipid whisker model of the structure of oxidized cell membranes. J Biol Chem 283(4):2385-2396

Grogan DW, Cronan JE Jr (1997) Cyclopropane ring formation in membrane lipids of bacteria. Microbiol Mol Biol Rev 61 (4):429-441

Gustot A, Smriti, Ruysschaert JM, McHaourab H, Govaerts C (2010) Lipid composition regulates the orientation of transmembrane helices in HorA, an ABC multidrug transporter. J Biol Chem 285(19):14144-14151

Hadley EB, Hancock RE (2010) Strategies for the discovery and advancement of novel cationic antimicrobial peptides. Curr Top Med Chem 10(18):1872-1881

Hammer MU, Brauser A, Olak C, Brezesinski G, Goldmann T, Gutsmann $\mathrm{T}$, Andra $\mathrm{J}$ (2010) Lipopolysaccharide interaction is decisive for the activity of the antimicrobial peptide NK-2 against Escherichia coli and Proteus mirabilis. Biochem J 427(3):477-488

Huang C (1969) Studies on phosphatidylcholine vesicles. Formation and physical characteristics. Biochemistry 8(1):344-352

Johnson RD, Schauerte JA, Wisser KC, Gafni A, Steel DG (2011) Direct observation of single amyloid-beta(1-40) oligomers on live cells: binding and growth at physiological concentrations. PLoS One 6(8):e23970

Junkes C, Harvey RD, Bruce KD, Dolling R, Bagheri M, Dathe M (2011) Cyclic antimicrobial R-, W-rich peptides: the role of peptide structure and E. coli outer and inner membranes in activity and the mode of action. Eur Biophys J 40(4):515-528

Karnovsky MJ, Kleinfeld AM, Hoover RL, Dawidowicz EA, McIntyre DE, Salzman EA, Klausner RD (1982) Lipid domains in membranes. Ann N Y Acad Sci 401:61-75

Klenk E, Padberg G (1962) On the gangliosides of horse erythrocytes. Hoppe Seylers Z Physiol Chem 327:249-255
Koprivnjak T, Peschel A (2011) Bacterial resistance mechanisms against host defense peptides. Cell Mol Life Sci 68(13):2243-2254

Kuhn R, Egge H (1963) Uber Ergebnisse Der Permethylierung Der Ganglioside Gi Und Gii. Chem Ber-Recl 96(12):3338

Kuhn R, Wiegandt H (1963) Die Konstitution Der Ganglioside Gii, Giii Und Giv. Z Naturforsch Pt B B 18(7):541

LaBach JP, White DC (1969) Identification of ceramide phosphorylethanolamine and ceramide phosphorylglycerol in the lipids of an anaerobic bacterium. J Lipid Res 10(5):528-534

Lohner K (2009) New strategies for novel antibiotics: peptides targeting bacterial cell membranes. Gen Physiol Biophys 28(2):105-116

Lohner K, Prossnigg F (2009) Biological activity and structural aspects of PGLa interaction with membrane mimetic systems. Biochim Biophys Acta 1788(8):1656-1666

Lundbaek JA, Collingwood SA, Ingolfsson HI, Kapoor R, Andersen OS (2010) Lipid bilayer regulation of membrane protein function: gramicidin channels as molecular force probes. J R Soc Interf 7 (44):373-395

Macdonald PM, Seelig J (1987) Calcium binding to mixed cardiolipinphosphatidylcholine bilayers as studied by deuterium nuclear magnetic resonance. Biochemistry 26(19):6292-6298

Macfarlane MG (1962) Characterization of lipoamino-acids as o-aminoacid esters of phosphatidyl-glycerol. Nature 196(4850):136

Maldonado AY, Burz DS, Shekhtman A (2011) In-cell NMR spectroscopy. Prog Nucl Magn Reson Spectrosc 59(3):197-212

Marsh D (1991) General features of phospholipid phase transitions. Chem Phys Lipids 57(2-3):109-120

Marsh D (2008) Protein modulation of lipids, and vice-versa, in membranes. Biochim Biophys Acta 1778(7-8):1545-1575

Palmer KJ, Schmitt FO (1941) X-ray diffraction studies of lipide emulsions. J Cell Compar Physl 17(3):385-394

Palmer KJ, Schmitt FO, Chargaff E (1941) X-ray diffraction studies of certain lipide-protein complexes. J Cell Compar Physl 18(1):43-47

Pangborn MC (1941) A new serologically active phospholipid from beef heart. Proc Soc Exp Biol Med 48(2):484-486

Papahadjopoulos D, Miller N (1967) Phospholipid model membranes. I. Structural characteristics of hydrated liquid crystals. Biochim Biophys Acta 135(4):624-638

Perly B, Smith IC, Jarrell HC (1985) Effects of replacement of a double bond by a cyclopropane ring in phosphatidylethanolamines: a $2 \mathrm{H}$ NMR study of phase transitions and molecular organization. Biochemistry 24(4):1055-1063

Peschel A (2002) How do bacteria resist human antimicrobial peptides? Trends Microbiol 10(4):179-186

Pizer FL, Ballou CE (1959) Studies on myo-inositol phosphates of natural origin. J Am Chem Soc 81(4):915-921

Porter NA, Wolf RA, Weenen H (1980) Free-radical oxidation of polyunsaturated lecithins. Lipids 15(3):163-167

Robertson JD (1957) Some aspects of the ultrastructure of double membranes. Prog Neurobiol 2:1-22, discussion 22-30

Rothman JE, Lenard J (1977) Membrane asymmetry. Science 195 (4280):743-753

Sani MA, Keech O, Gardestrom P, Dufourc EJ, Grobner G (2009) Magic-angle phosphorus NMR of functional mitochondria: in situ monitoring of lipid response under apoptotic-like stress. FASEB J 23(9):2872-2878

Sani MA, Gehman JD, Separovic F (2011a) Lipid matrix plays a role in Abeta fibril kinetics and morphology. FEBS Lett 585(5):749-754

Sani MA, Whitwell TC, Separovic F (2011b) Lipid composition regulates the conformation and insertion of the antimicrobial peptide maculatin 1.1. Biochim Biophys Acta (in press)

Schneider T, Kruse T, Wimmer R, Wiedemann I, Sass V, Pag U, Jansen A, Nielsen AK, Mygind PH, Raventos DS, Neve S, Ravn B, Bonvin AM, De Maria L, Andersen AS, Gammelgaard LK, Sahl HG, Kristensen HH (2010) Plectasin, a fungal defensin, targets the bacterial cell wall precursor Lipid II. Science 328(5982):1168-1172 
Selenko P, Wagner G (2007) Looking into live cells with in-cell NMR spectroscopy. J Struct Biol 158(2):244-253

Serber Z, Dotsch V (2001) In-cell NMR spectroscopy. Biochemistry 40(48):14317-14323

Serber Z, Ledwidge R, Miller SM, Dotsch V (2001) Evaluation of parameters critical to observing proteins inside living Escherichia coli by incell NMR spectroscopy. J Am Chem Soc 123(37):8895-8901

Serber Z, Selenko P, Hansel R, Reckel S, Lohr F, Ferrell JE Jr, Wagner G, Dotsch V (2006) Investigating macromolecules inside cultured and injected cells by in-cell NMR spectroscopy. Nat Protoc 1 (6):2701-2709

Sevcsik E, Pabst G, Jilek A, Lohner K (2007) How lipids influence the mode of action of membrane-active peptides. Biochim Biophys Acta 1768(10):2586-2595

Shai Y (2002) Mode of action of membrane active antimicrobial peptides. Biopolymers 66(4):236-248

Simons K, Ikonen E (1997) Functional rafts in cell membranes. Nature 387(6633):569-572

Singer SJ, Nicolson GL (1972) The fluid mosaic model of the structure of cell membranes. Science 175(4023):720-731

Sperry WM (1926) Lipid excretion. III. Further studies of the quantitative relations the fecal lipids. J Biol Chem 68(2):0357-0383

Stier A, Sackmann E (1973) Spin labels as enzyme substrates. Heterogeneous lipid distribution in liver microsomal membranes. Biochim Biophys Acta 311(3):400-408
Takayama K, Qureshi N, Mascagni P, Nashed MA, Anderson L, Raetz CR (1983) Fatty acyl derivatives of glucosamine 1-phosphate in Escherichia coli and their relation to lipid A. Complete structure of A diacyl GlcN-1-P found in a phosphatidylglycerol-deficient mutant. J Biol Chem 258(12):7379-7385

Verdon J, Labanowski J, Sahr T, Ferreira T, Lacombe C, Buchrieser C, Berjeaud JM, Hechard Y (2011) Fatty acid composition modulates sensitivity of Legionella pneumophila to warnericin RK, an antimicrobial peptide. Biochim Biophys Acta 1808(4):1146-1153

Vitali B, Turroni S, Serina S, Sosio M, Vannini L, Candela M, Guerzoni ME, Brigidi P (2008) Molecular and phenotypic traits of in-vitroselected mutants of Bifidobacterium resistant to rifaximin. Int $\mathrm{J}$ Antimicrob Agents 31(6):555-560

Wiedemann I, Breukink E, van Kraaij C, Kuipers OP, Bierbaum G, de Kruijff B, Sahl HG (2001) Specific binding of nisin to the peptidoglycan precursor lipid II combines pore formation and inhibition of cell wall biosynthesis for potent antibiotic activity. J Biol Chem 276(3):1772-1779

Willumeit R, Kumpugdee M, Funari SS, Lohner K, Navas BP, Brandenburg K, Linser S, Andra J (2005) Structural rearrangement of model membranes by the peptide antibiotic NK-2. Biochim Biophys Acta 1669(2):125-134

Wilmes M, Cammue BP, Sahl HG, Thevissen K (2011) Antibiotic activities of host defense peptides: more to it than lipid bilayer perturbation. Nat Prod Rep 28(8):1350-1358 